\title{
Status of Correlation between Radiographic Image and Pathologic Finding
}

National Cancer Institute

\section{Source}

National Cancer Institute. Status of Correlation between Radiographic Image and

Pathologic Finding. NCI Thesaurus. Code C137938.

A qualifier used to describe the agreement between radiographic and pathologic findings. 